\title{
grim, a novel cell death gene
in Drosophila
}

\author{
Po Chen, William Nordstrom, Bridget Gish, ${ }^{1}$ and John M. Abrams ${ }^{2}$
}

Department of Cell Biology and Neuroscience, University of Texas Southwestern Medical Center, Dallas, Texas 75235-9039 $\mathrm{USA}^{1}$ Department of Molecular Biology and Oncology, University of Texas Southwestern Medical Center, Dallas, Texas 75235-9148 USA

\begin{abstract}
A genomic interval at $75 \mathrm{C1}, 2$ is required for programmed cell death in Drosophila. We identified a new activator of apoptosis, grim, which maps between two previously identified cell death genes in this region reaper (rpr) and head involution defective (hid). Expression of grim RNA coincided with the onset of programmed cell death at all stages of embryonic development, whereas ectopic induction of grim triggered extensive apoptosis in both transgenic animals and in cell culture. Cell killing by grim was blocked by coexpression of $\mathrm{p} 35$, a viral product that inactivates ICE-like proteases, and did not require the functions of rpr or hid. The predicted grim protein shares an amino-terminal motif in common with rpr. However, grim was sufficient to elicit apoptosis in at least one context, where rpr was not. The grim gene product might thus function in a parallel circuit of cell death signaling that ultimately activates a common set of downstream apoptotic effectors.
\end{abstract}

[Key Words: Apoptosis; programmed cell death; Drosophila]

Received May 3, 1996; revised version accepted June 6, 1996.

Programmed cell death (PCD) or apoptosis is an essential regulator of tissue homeostasis as animals develop and age (Saunders and Fallon 1967; Truman 1984; Hurle 1988; Ellis et al. 1991; Oppenheim 1991; Raff 1992). The importance of elucidating the molecular basis underlying this process is underscored by a number of recent studies that implicate the misregulation of PCD in the pathophysiology of several human diseases, including AIDS (Meyaard et al. 1992; Gougen and Montagnier 1993), neurodegenerative disease (Roy et al. 1995; Liston et al. 1996; Vito et al. 1996), and cancer (for review, see Williams 1991).

Several lines of evidence suggest that the physiology of apoptosis is quite highly conserved. First, the morphological changes associated with programmed cell deaths are strikingly similar in both vertebrates and invertebrates (Kerr et al. 1972; Wyllie et al. 1980; Kerr and Harmon 1991; Abrams et al. 1993). Second, at least two essential cell death genes in Caenorhabditis elegans, ced-3 and ced-9, are members of gene families that encode apoptotic functions in vertebrates (for review, see Steller 1995; White 1996). Third, viral proteins that suppress apoptosis in their hosts (p35 and crmA) can exhibit potent anti-apoptotic activity in a wide range of heterologous species (Rabizadeh et al. 1993; Hay et al. 1994; Sugimoto et al. 1994; Grether et al. 1995; Pronk et al. 1996; White et al. 1996; W. Nordstrom, P. Chen, H. Steller, and J.M. Abrams, in prep.).

${ }^{2}$ Corresponding author.
In Drosophila melanogaster, a genomic interval defined by the $\mathrm{H} 99$ deletion mutation is required for embryonic PCD (Abrams et al. 1993; White et al. 1994; Abrams 1996). This region spans $\sim 300 \mathrm{~kb}$ of DNA that includes at least two cell death genes, reaper (rpr) (White et al. 1994) and head involution defective (hid) (Grether et al. 1995). The former gene product is thought to share similarities with the "death domain" of the FAS/TNFR1 protein family (Cleveland and Ihle 1995; Golstein et al. 1995a,b|, whereas the latter shares no extensive sequence similarity to known proteins. Although the distribution of RNA from both genes generally corresponds to embryonic patterns of apoptosis, only rpr appears to be selectively expressed in all cells that will later undergo programmed cell death.

Although no apoptosis occurs in embryos bearing homozygous deletions of the entire $\mathrm{H} 99$ interval (Abrams et al. 1993; White et al. 1994), null mutations at hid display only mild cell death defects (Grether et al. 1995) and, to date, no single-gene mutants of rpr have been identified. Therefore, the precise number of cell death genes uncovered by H99 is not known. Phenotypes associated with two informative deletions in the region, X14 and X25 (White et al. 1994; Grether et al. 1995), raised the possibility that perhaps one or more additional cell death genes might reside between hid and rpr. Both strains partially uncover the $\mathrm{H} 99$ interval from the distal boundary, thereby eliminating hid yet preserving $r p r$. However, although both deletions exhibit mild and indistinguishable PCD phenotypes as homozygotes 
(Grether et al. 1995), X25 uncovers a far more severe phenotype when placed in trans to H99 than does X14. Whereas X14/H99 embryos show subtle cell death defects similar to those observed for hid null alleles, X25/ H99 transheterozygotes exhibit a severe reduction in apoptosis frequency that can be easily visualized by staining with acridine orange (Grether 1994; J.M. Abrams, unpubl.). Because the relevant breakpoint of X25 is $\sim 60$ $\mathrm{kb}$ more proximal than that of X14 (Grether 1994), it was possible that one or more additional cell death functions mapped to the interval bounded by these breakpoints.

In this report we describe our characterization of a newly identified cell death gene, grim, which maps between the relevant breakpoints of X14 and X25. A genomic cosmid spanning the grim gene restored apoptosis to H99 embryos, and grim RNA was specifically found in regions associated with $\mathrm{PCD}$. Moreover, ectopic expression of a grim cDNA triggered extensive cell death in embryos, eye discs, and cultured cells. These cell deaths did not require Rpr or Hid and could be prevented by coexpression of the viral anti-apoptotic protein $\mathrm{p} 35$. We therefore propose that the apoptotic function encoded by grim is upstream of putative cysteine proteases (targets of $\mathrm{p} 35$ ) and that Grim activity parallels that of RPR and HID. Finally because grim triggered extensive apoptosis in at least one developmental context where Rpr was not sufficient, it is possible that these proteins enter a common apoptotic pathway at different sites.

\section{Results}

\section{Identification and molecular characterization of grim}

To test for possible cell death functions in the interval between the proximal breakpoints of DfX14 and DfX25, we produced four independent germ-line transformants with a cosmid clone that spans the appropriate region. Three of these were tested in a homozygous H99 background for restoration of embryonic cell death by acridine orange (AO) staining (Abrams et al. 1993). We found that substantial numbers of apoptotic cell deaths are restored to virtually all mutant embryos bearing four doses of the grim cosmid (Fig. 1). All three transformant lines
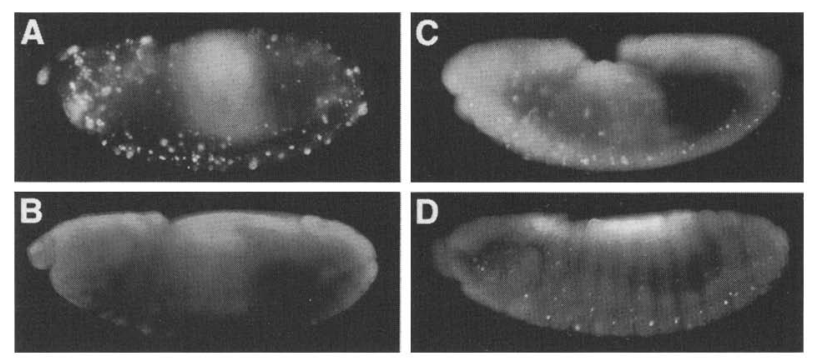

Figure 1. A cosmid spanning grim restores apoptosis to H99 embryos. AO staining of an embryo from the parental yw strain $(A)$, a $\mathrm{H} 99$ homozygote $\{B \mid$, and $\mathrm{H} 99$ embryos carrying four doses of the grim cosmid transgene $(C, D)$. The embryo in $D$ is typical of a majority of rescued mutants, whereas the phenotype shown in $C$ is observed only occasionally. examined showed similar levels of rescue, and this activity was dose dependent, as four doses of the cosmid showed more rescue than two doses. Note that these cell deaths occur in the absence of two other cell death genes in the $\mathrm{H} 99$ region, rpr and hid. The partial nature of this phenotypic rescue was reminiscent of the behavior of H99 transformants bearing a rpr cosmid. We therefore counted apoptotic cells in $\mathrm{H} 99$ embryos bearing similar doses of the rpr or the grim transgene. Because they are only partially rescued for cell death and still defective for head involution, embryos with these genotypes are easily identified. In these studies we found that the extent of rescue conferred by four doses of grim was indistinguishable from that conferred by four doses of $r p r$. It is worth noting here that artifactual explanations for the restoration of $\mathrm{PCD}$ can be ruled out because other transgenes, including at least one cosmid, did not rescue apoptosis in H99 embryos (White et al. 1994; Grether et al. 1995).

We identified one transcription unit that mapped to a single $\sim 3-\mathrm{kb}$ Hpal-NotI fragment within this cosmid clone at a position that lies $\sim 20 \mathrm{~kb}$ distal to the proximal breakpoint of X25. This fragment was used to isolate eight hybridizing clones from an embryonic cDNA library (see Materials and methods). These all contained inserts of $\sim 1.6-\mathrm{kb}$, and the clone selected for sequence analysis (clone $\mathrm{A}$ ) included an extensive poly(A) tail. By virtue of its proximity to $r p r$ and its potent cell killing activity (see below) we assigned the name grim to this gene.

grim cDNA detected a single $1.6-\mathrm{kb}$ transcript by Northern blot analysis of embryonic RNA and, as expected, also recognized a $\sim 5-\mathrm{kb}$ EcoRI genomic band that is present in wild-type flies but absent in homozygous H99 embryos (not shown). These data confirmed that our cDNA clones correspond to expressed sequences from within the $\mathrm{H} 99$ interval. Using PCR analyses of genomic DNA and partial sequencing of the grim cosmid, no apparent intronic sequences were found. By mapping the cDNA clone onto the cosmid, we determined that grim is transcribed toward the telomere in an orientation that parallels the direction of rpr and hid expression.

The complete sequence of grim cDNA clone A was determined (Fig. 2) and confirmed by sequencing genomic-derived PCR products and parts of the grim cosmid. The longest deduced open reading frame (ORF) in the $5^{\prime} \rightarrow 3^{\prime}$ direction is a protein of 138 amino acids that was validated in tests for apoptosis functions (see Table 1; Fig. 5, below). The predicted Grim protein has an estimated pI of 5.8, no helical trans-membrane domains (Rost and Sander 1994), and shares no significant homology to any sequence in the data base as analyzed using BLAST (Altschul et al. 1990). However, direct inspection shows that the amino-terminal end of this predicted protein shares very notable similarity to Rpr and less similarity to Hid (Fig. 2). Ten of the first 14 residues of Grim are identical to the corresponding position in Rpr, whereas three of the remainder are conserved substitutions. This region of Rpr also shares notable but less similarity to the Hid protein (Grether et al. 1995). A 


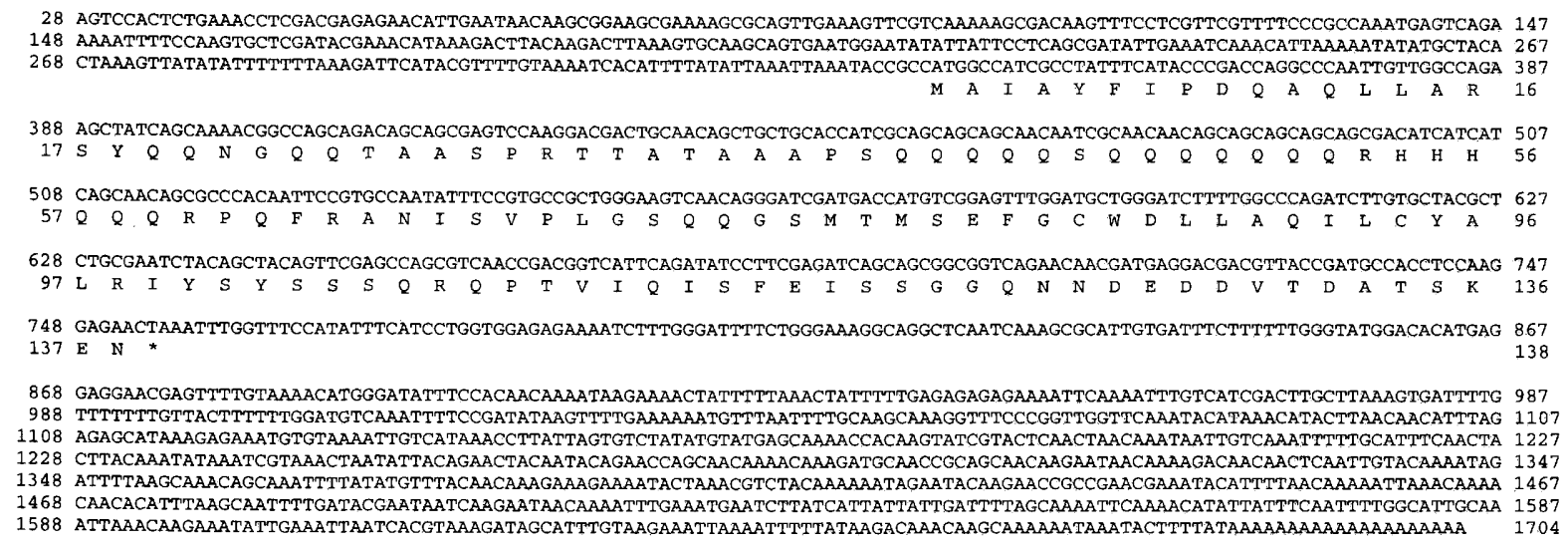

B

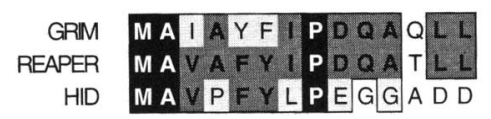

Figure 2. Sequence analysis of grim. (A) grim cDNA sequence and deduced amino acid sequence of grim ORF. The predicted Grim protein is 138 amino acids long with a central stretch rich in glutamine. (B) Alignment of the first 14 amino acids of Rpr, Grim, and Hid. The predicted amino acid sequence of grim ORF shares extensive similarity with Rpr and some similarity with Hid at the amino termini. Residues in black boxes are identical among all three proteins. Darkly shaded residues are identities between Rpr and either Grim or Hid. Lightly shaded amino acids are conserved substitutions relative to Rpr.

three-way comparison within this region suggests that Rpr and Grim share the most similarity to each other while Grim and Hid share the least.

\section{Embryonic expression of grim RNA resembles the embryonic PCD pattern}

We used in situ hybridization with digoxigenin-labeled RNA probes to examine grim expression during embryonic development. The overall distribution of grim RNA distinctly resembled patterns of embryonic PCD (Fig. 3). At each stage of embryogenesis, grim RNA is present in regions and tissues where cell death occurs. Examples shown in Figure 3 illustrate this relationship during germ band retraction and in the condensing ventral nerve cord of a stage 16 embryo. The onset of grim expression occurred in stage 11 embryos (initiation of extensive PCD occurs in stage 12). No hybridization was detected in $\mathrm{H} 99$ embryos (not shown). Interestingly, gross patterns of grim expression were similar to patterns observed for $r p r$ and hid. A notable exception, however, is that hid expression does not correlate with PCD in the embryonic nerve cord at stage 16 /Grether et al. 1995), whereas signals for both grim (Fig. 3C) and rpr (White et al. 1994) are clearly found in this location.

We also detected signal for grim RNA that was subcellularly localized inside some, but not all, macrophages (Fig. 3E,F) (Abrams et al. 1992, 1993). This distribution, also found with probes for rpr (White et al. 1994; Zhou et al. 1995) and hid RNAs (Grether et al. 1995), probably reflects hybridization to mRNAs inside corpses that have recently been engulfed by phagocytic cells and
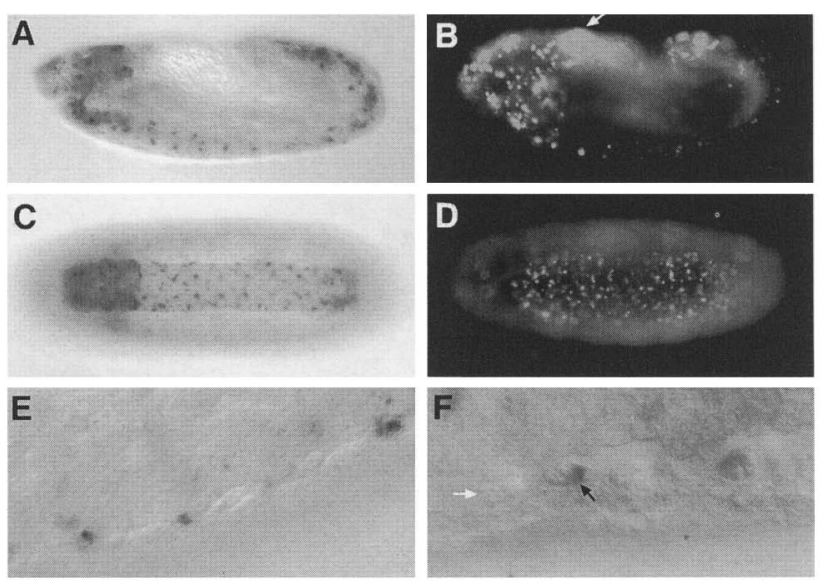

Figure 3. grim expression coincides with patterns of embryonic PCD. Shown are in situ hybridizations with a grim-specific probe $(A, C, E, F)$ and similarly staged embryos stained with $\mathrm{AO}$ for comparison $(B, D)$. $A$ and $B$ are lateral views of late stage 12 embryos (during germ band retraction). The arrow in $B$ indicates nonspecific fluorescence attributable to the prominence of yolk in this region. $C$ and $D$ are ventral views of the nerve cord in stage 16 embryos. $E$ (lower magnification) and $F$ (higher magnification) show large, wandering macrophages (arrows in $F$ ) in embryos analyzed for grim expression. Note that a compartmentalized signal is detected in some of these cells /black arrow in $F)$ and is absent from others (white arrow in $F$ ). 
may be characteristic of cell death activators mapping to $75 \mathrm{Cl}, 2$ in Drosophila.

grim is sufficient to induce cell death that can be blocked by coexpression of p35

To determine whether grim encodes apoptotic activity, we examined the consequences of ectopic grim expression in a variety of experimental contexts. A grim cDNA was cloned into the pGMR vector (pGMR-grim) that directs specific expression to the developing eye (Hay et al. 1994), and this construct was used to isolate a total of eight independent germ-line transformants. As homozygotes, seven of these exhibit the severe eye-ablation phenotype illustrated in Figure $4 \mathrm{C}$, whereas one strain showed no obvious effects. Heterozygotes for the GMRgrim trangene exhibit varying degrees of intermediate phenotypes (Fig. 4B), with eyes that are substantially smaller than wild type and display a characteristic rough appearance.

We also tested whether this eye-ablation phenotype could be affected by the anti-apoptotic protein $\mathrm{p} 35$, a baculovirus protein that functions to block cell death by inactivating proteases of the ICE/CED-3 family /Clem et al. 1991; Miura et al. 1993; Clem and Miller 1994; Bump et al. 1995; Xue and Horvitz 1995). To examine this issue, we produced strains that simultaneously express both grim and p35 transgenes (Hay et al. 1994) in the developing eye. Figure 4D shows that eyes of these coexpressing flies are restored to a wild-type size and normal organization. Thus, p35 can suppress the retinal cell death phenotype associated with ectopic grim expression.

We also examined the consequence of grim expression in cultured cells. Drosophila SL2 cells (Schneider 1972) were transfected with pMT-grim, a plasmid designed to conditionally express the grim cDNA from an upstream metal-inducible promoter (Bunch et al. 1988; Kovach et al. 1992). In both transient assays and in stably transfected populations, potent cell killing associated with grim induction was observed. Within $4 \mathrm{hr}$ of metal treatment, considerable numbers of apoptotic figures can be found in cultures transfected with pMT-grim and by $9 \mathrm{hr}$ apoptotic death is very extensive (Fig. 5B). This effect is indistinguishable from cultures in which rpr has been similarly induced (W. Nordstrom, P. Chen, H. Steller, and J.M. Abrams, in prep.) and is not observed in controls.

We used two independent methods to measure apoptosis in our studies. Figure $5 \mathrm{C}$ shows the results of flow cytometry assays that rely on the appearance of "hypodiploid nuclei" in samples stained with propidium iodide. In cultured cells, the appearance of nuclei with a "sub-G1" DNA content is a characteristic determinant of apoptosis and can be used to assess the extent of apoptotic death (Tounekti et al. 1995; W. Nordstrom, P. Chen, H. Steller, and J.M. Abrams, in prep.). In transiently transfected samples, a substantial fraction of pMT-grim cells underwent apoptosis after $16 \mathrm{hr}$ of metal treatment, whereas only background levels of cell death occurred in the absence of copper or in control cells that were transfected either with empty vector or an irrelevant protein expressed from the same vector (pMT-HAhook) (Kramer and Phistry 1996). Note that the percent apoptotic nuclei in Figure 5C is not normalized for transient transfection efficiencies, which typically range from $\sim 40 \%-60 \%$ in our assays. Therefore, the extent of apoptosis after grim induction is likely to be substantially higher than is indicated by the absolute percentage of hypodiploid nuclei.

We corroborated these findings with an alternative assay for cell killing that also detects rpr-induced apoptosis (W. Nordstrom, P. Chen, H. Steller, and J.M. Abrams, in prep.) and relies on the loss of cotransfected reporter activity after induction of the test plasmid (Hsu et al. 1995). In this case, the number of cells positive for a cotransfected actin promoter-driven LacZ reporter, pAct-LacZ, was determined $16 \mathrm{hr}$ after induction $164 \mathrm{hr}$ after transfection; see Materials and methods|. Treatment with metals alone had no effect on the number of
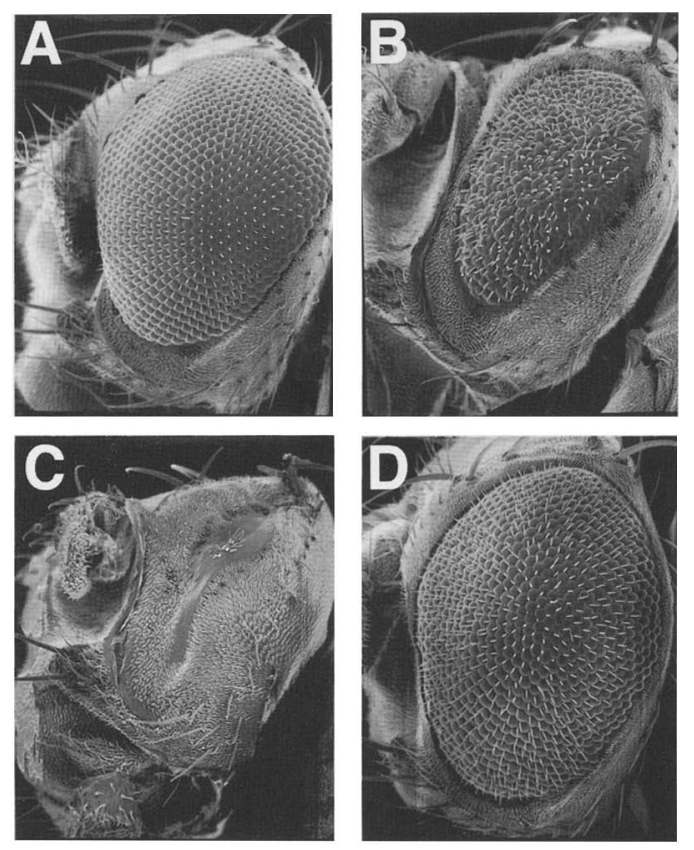

Figure 4. A dramatic phenotype caused by ectopic expression of grim in the developing eye can be prevented by coexpression of the baculovirus p35 protein. Scanning electron micrographs of the compound eye of the parental strain $y w(A)$, pGMRgrim1/ + (B), pGMR-grim1/pGMR-grim1 $(C)$, and pGMRgrim1/pGMR-grim1; pGMR-p35/pGMR-p35 (D). Transgenic flies containing a single copy of pGMR-grim1 $(B)$ exhibit a reduced number of disordered ommatidia and mechanosensory bristles. Two copies of the pGMR-grim1 transgene $(C)$ causes a complete elimination of ommatidia with only a few bristles remaining. Seven of eight independent transformants had this phenotype. The compound eyes of flies homozygous for both pGMR-grim 1 and pGMR-p35 transgene insertions $(D)$ are restored to the wild-type size. Note: Apparent differences in magnification between samples reflects different positioning on electron microscope stage. 

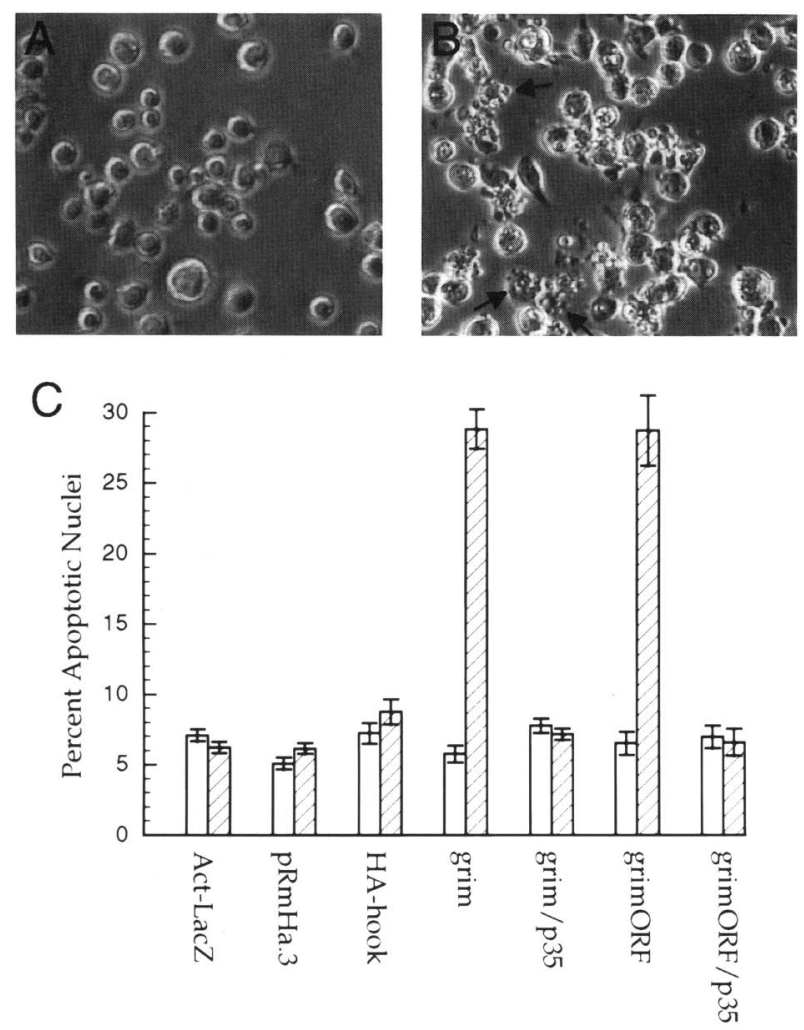

Figure 5. Induction of grim expression triggers apoptosis in culture, which is prevented by $\mathrm{p} 35$. (A) Photomicrographs of SL2 cells; $(B)$ cells stably transfected by pMT-grim treated for $9 \mathrm{hr}$ with $\mathrm{CuSO}_{4}$. Arrows in $B$ indicate cells with a characteristic apoptotic appearance. The pictures were taken under a $40 \times$ lens using a CCD camera. (C) Flow cytometric assays for apoptosis in transiently transfected cultures. Drosophila SL2 cells were transiently transfected alone with pActin-LacZ $(0.2 \mu \mathrm{g})$ or cotransfected with pActin-LacZ $(0.2 \mu \mathrm{g})$ plus empty vector pRmHa.3 (2 $\mu \mathrm{g})$, pMT-HA-hook (2 $\mu \mathrm{g})$, pMT-grim (2 $\mu \mathrm{g})$, pMTgrimORF $(2 \mu \mathrm{g})$, or pMT-grim/pMT-p35 $(2 / 3 \mu \mathrm{g})$, and processed for FACScan as described in Materials and methods. Shown are percent of apoptotic (hypodiploid) nuclei obtained from triplicate samples of control (open) or copper (hatched)treated samples.

LacZ-positive cells nor did controls with empty vector or an irrelevant protein (Table 1). In contrast, a drastic reduction of $\beta$-gal-expressing cells occurred in metaltreated cells that had been transfected with pMT-grim, and many of the remaining lacZ-positive cells in the grim-induced cultures exhibited classic apoptotic morphology. We conclude that the grim gene product is a potent activator of apoptosis. To confirm that the ORF predicted from our cDNA sequence analysis is responsible for cell killing, we tested pMT-grimORF, a plasmid that directs metal-inducible expression of the predicted 138 amino acid protein (see Fig. 2). As illustrated in Table 1 and Figure 5C, this construct encodes levels of apoptotic activity that are indistinguishable from the fulllength cDNA.

We also took advantage of this culture system to test more directly the effects of p35 on grim-induced cell killing. For these studies we used pMT-p35 a metal-inducible version of p35 (W. Nordstrom, P. Chen, H. Steller, and J.M. Abrams, in prep.). Consistent with our observations in the developing eye (Fig. 4), coexpression of p35 completely abrogated grim-mediated apoptosis in this context as well (Table 1; Fig. 5C). This result indicates that the function of grim may reside upstream of one or more ICE-like proteases that are targeted by $\mathrm{p} 35$.

We also produced germ-line transformants with a heat-inducible transgene, heat shock-grim and found that ectopic expression of grim in this context also caused extensive cell death throughout the embryo (two independent strains tested). Within $1 \mathrm{hr}$ of heat treatment, excessive apoptosis was scored by AO and TUNEL staining (Fig. 6) in $>70 \%$ of HS-grim embryos, whereas no appreciable elevation of apoptosis was observed in control embryos that were heat-shocked but lacked the transgene (Fig. 6A) (see also White et al. 1994; Grether et al. 1995). Gross morphological abnormalities as a consequence of ectopic cell death and severe organismal lethality were two additional phenotypes associated with heat-induced grim expression. After heat treatment /see Materials and methods|, no HS-grim embryos hatched,
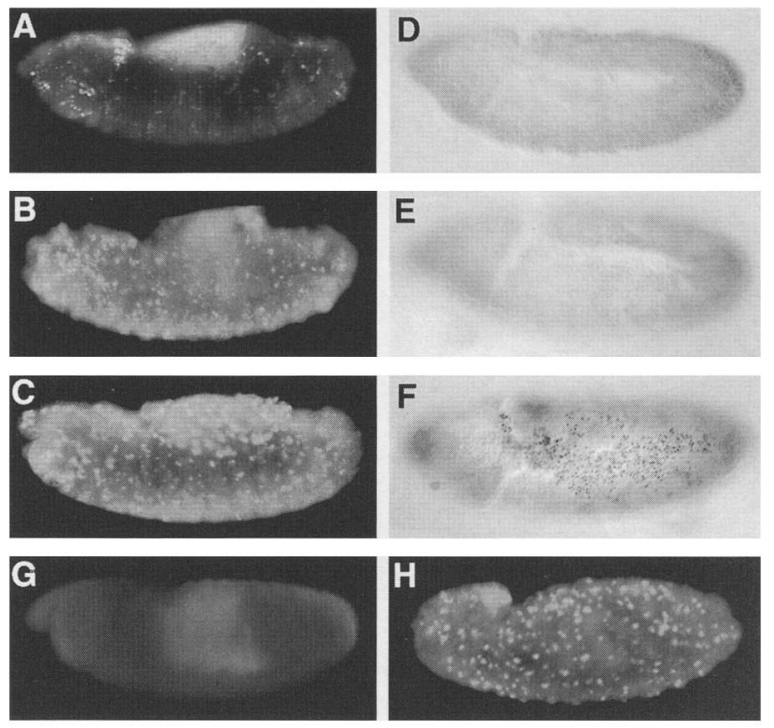

Figure 6. Apoptosis induced by grim in wild-type and H99 embryos. yw embryos $(A, D)$ or embryos bearing a heat-inducible grim transgene, HS-grim $(C, F)$ or a heat-inducible rpr transgene, hsrpr $(B, E)$ were heat-treated for $30 \mathrm{~min}$ and analyzed $1 \mathrm{hr}$ later (see Materials and methods). (A-C) Stage 13/14 embryos stained with AO. $(D-F)$ Stage 9 embryos labeled for apoptotic cells by TUNEL. Note that although grim and $r p r$ both induce cell death during later stages of embryonic development $\mid \mathrm{cf}$. $B$ and $C$ with $A$ ), only grim triggers apoptosis at the earlier stage (cf. $F$ and $E$ ). grim-induced apoptosis also occurs in embryos deleted for the H99 region $(G, H)$. AO staining is shown in a heat-shocked $\mathrm{H} 99$ embryo $(G)$ or in a heat-shocked HS-grim2, H99 embryo $(H)$. Embryos homozygous for $\mathrm{H} 99$ were identified by their hid phenotype. 
Chen et al.

Table 1. Cell death induced by Grim

\begin{tabular}{lccccc}
\hline \multirow{2}{*}{$\begin{array}{l}\text { Copper } \\
\text { treatment }\end{array}$} & \multicolumn{5}{c}{ Blue cells per field } \\
\cline { 2 - 6 } & Actin-LacZ & pRmHa.3 & HA-hook & grim & grimORF \\
\hline No & $150 \pm 9$ & $150 \pm 13$ & $138 \pm 9$ & $147 \pm 5$ & $160 \pm 16$ \\
Yes & $141 \pm 7$ & $162 \pm 15$ & $148 \pm 12$ & $39 \pm 6$ & $31 \pm 5$ \\
\hline
\end{tabular}

Drosophila SL2 cells were transiently transfected with pActin-LacZ $(0.2 \mu \mathrm{g})$ alone, or cotransfected with pActin-LacZ $(0.2 \mu \mathrm{g})$ plus empty vector pRmHa.3 $(2 \mu \mathrm{g})$, pMT-HA-hook $(2 \mu \mathrm{g})$, pMT-grim $(2 \mu \mathrm{g})$, pMT-grimORF $(2 \mu \mathrm{g})$, or pMT-grim and pMT-p35 (2 and 3 $\mu \mathrm{g}$, respectively). Cells from each well were split to two wells $48 \mathrm{hr}$ after transfection, and copper was added to one of the wells. Cells were fixed and stained with X-gal $16 \mathrm{hr}$ later as described in Materials and methods. $\beta$-Galactosidase activity data are presented as average number of $\beta$-gal-positive (blue) cells $( \pm$ S.D.) per field $(10 \times$ lens) for at least three fields from each of three independent transfections.

whereas $>85 \%$ of control embryos exposed in parallel did.

The conditional phenotypes associated with HS-grim are similar to those documented for HS-rpr transformants (White et al. 1996). We therefore conducted a detailed comparison of the apoptotic responses of these strains at various embryonic stages. Interestingly, we found that induction of HS-grim could trigger substantial cell deaths during early embryogenesis at a time when HS-rpr failed to provoke any apoptotic response (Fig. 6E). Because these are stages prior to the initiation of PCD in wild-type embryonic development (Abrams et al. 1993/ we used TUNEL to score cell death and also confirm their apoptotic character. Although HS-rpr was unable to induce cell death at stage 9 or earlier, many TUNEL-positive cells were frequently observed in HSgrim embryos at this stage (Fig. 6F). These findings were corroborated in two independent HS-rpr strains and two independent HS-grim strains and are therefore not dependent on insertion site effects. The ability of grim to induce cell death in a developmental context where rpr does not suggests that the activity or regulation of these proteins may be distinct.

\section{The cell death function of grim is independent of rpr and hid}

To determine whether grim-induced apoptosis requires other functions in the H99 region, we tested the ability of HS-grim transgenes to trigger cell death in homozygous embryos that are deleted for this interval. In a collection of embryos from parents that are heterozygous for $\mathrm{H} 99$ and homozygous for the HS-grim transgene, $25 \%$ will be cell death defective and easily scored by an absence of $\mathrm{AO}$ staining. After heat treatment, however, prominent $\mathrm{AO}$ staining occurred in $100 \%$ of embryos from parents of this genotype (as in Fig. 6C) suggesting that grim-induced apoptosis occurred even in embryos homozygous for H99. At later embryonic stages we were, able to still distinguish the hid defect even though cell death was restored to $\mathrm{H} 99$ homozygotes. Figure 6, G and $\mathrm{H}$, illustrates this observation showing that within $1 \mathrm{hr}$ after heat treatment, induced grim expression is sufficient to trigger extensive cell death among embryos that bear the characteristic hid phenotype. Appreciable induction of apoptosis does not occur in the absence of heat shock nor does it occur in heat-shocked embryos from the parental strains. Moreover, several irrelevant control transgenes (including engrailed, hedgehog, and disco) also expressed from the $h s p 70$ promoter have been tested similarly and do not trigger apoptosis in $\mathrm{H} 99 \mathrm{em}$ bryos (Grether et al. 1995). Our results clearly show that grim-induced apoptosis does not require the function of other cell death genes in the H99 interval.

Because expression of rpr RNA anticipates both normal PCD (White et al. 1994) and ectopically induced apoptosis (W. Nordstrom, P. Chen, H. Steller, and J.M. Abrams, in prep.) we investigated the possibility that grim-induced cell death might be associated with crossregulation at the rpr locus. However, when HS-grim embryos were examined after heat shock by in situ hybridization for altered expression of rpr, no significant effects on the distribution of rpr RNA were observed (not shown|. Conversely, it was also possible that the functions of $r p r$ and hid might influence grim expression. We therefore examined grim RNA expression in heatshocked rpr (hsrpr) embryos (White et al. 1996) and in embryos homozygous for hid ${ }^{W R+X 1}$, a null mutation in hid (Abbot and Lengyel 1991; Grether et al. 1995). Again, no evidence for cross-regulatory interactions was obtained, as the distribution of grim RNA in both instances was indistinguishable from wild type (not shown). Taken together, these results establish that grim functions independently of rpr or hid as an activator of PCD.

\section{Discussion}

Deletion mutations that uncover a $\sim 300-\mathrm{kb}$ genomic interval at $75 \mathrm{Cl}, 2$ prevent all apoptotic deaths in the Drosophila embryo. So far, two activators of PCD, rpr (White et al. 1994) and hid (Grether et al. 1995), have been mapped to this interval. However, several lines of evidence were consistent with, or implicated, at least one additional cell death function uncovered by the H99 deletion. Strains X14 and X25 have proximal breakpoints within the H99 interval, and although both deletions retain rpr and remove hid, they behave differently when placed in trans to H99. This observation prompted us to test for additional cell death functions in the region with specific emphasis on DNA proximal to hid and distal to rpr. In this report we describe a gene in this location, grim, which is itself a potent activator of cell death and 
defines the third apoptotic function in the $\mathrm{H} 99$ genomic interval.

grim encodes a potent apoptotic function

Several lines of evidence established that grim encodes an activator of PCD. First, germ-line transformation of genomic DNA spanning the grim locus resulted in restoration of cell death to H99 mutant embryos. Although only partial rescue of the cell death defect by the grim cosmid was observed, the extent of rescue was dose dependent and similar to levels of rescue obtained by corresponding doses of genomic rpr DNA. Second, the amino-terminal portion of Grim shares conspicuous similarity to Rpr, a protein already well established as an activator of cell death in Drosophila (White et al. 1994, 1996; Pronk et al. 1996; W. Nordstrom, P. Chen, H. Steller, and J.M. Abrams, in prep.). Third, the induction of grim either in cultured cells or in ectopic tissues triggered extensive cell death that was apoptotic in appearance, prevented by a viral inhibitor of apoptosis, and detected by methods that are selective for this form of cell death (AO (Abrams et al. 1993) and TUNEL (Gavrieli et al. 1992)]. These results argue strongly for an apoptotic mode of cell killing induced by grim. Finally, the distribution of grim transcript during embryogenesis is coincident with patterns of embryonic cell death, and we occasionally detect compartmentalized signals for grim RNA inside phagocytes. This feature is an unusual staining characteristic that has also been observed with probes for rpr (White et al. 1994; Zhou et al. 1995) and hid (Grether et al. 1995) and probably reflects hybridization to RNAs that persist within engulfed cell corpses. These observations suggest that like RNA expressed from rpr and hid, that from the grim gene anticipates the onset of cell death.

Although not yet proven formally, the consequences of ectopic grimORF expression strongly suggest that grim activity is mediated by a protein product that provides an associated cell autonomous function. The mechanism by which grim elicits the apoptosis program remains to be determined as does the functional significance of amino-terminal motif shared among grim, rpr, and hid. In contrast to reported alignments between Rpr and some death domain proteins (Cleveland and Ihle 1995; Golstein et al. 1995a,b) no similar alignments were detected for Grim.

\section{Genetics of the H99 cell death interval}

grim is the third gene mapped to the $\mathrm{H} 99$ deletion mutation thus far. In addition to rpr and hid, evidence from synthetic deletions (see introductory section) had implicated at least one more cell death function in the region. Although grim clearly meets all requisite criteria for this predicted function, we cannot rule out the possibility that additional PCD genes may reside in the $\mathrm{H} 99$ interval. Genetic approaches to this problem are hampered by the fact that only alleles of hid were recovered from very extensive screens for chemically induced lethal muta- tions in the H99 interval (Abbot and Lengyel 1991; White et al. 1994; Grether et al. 1995). These lesions have been examined carefully and, although they do exhibit partial cell death phenotypes, hid mutants are distinctly less severe than the complete apoptotic failure exhibited by H99 (Grether et al. 1995). It is plausible that hid, rpr, and grim might encode partially redundant functions, which could account for the absence of singlegene lesions that phenocopy H99 and our inability to recover single gene lesions in grim or rpr. According to this scenario, more fully penetrant cell death phenotypes could require the disruption of at least two of the three known elements in the region; therefore, single-gene mutations other than hid might be inaccessible by screens for lethal or visible phenotypes. Conversely, simultaneous rescue of both rpr and grim functions might restore individuals to a phenocopy of the hid mutation. We investigated this possibility by examining $\mathrm{H} 99 \mathrm{em}-$ bryos that were homozygous for both grim and rpr cosmid transgenes. This genotype did not result in a phenocopy of hid, as these individuals were indistinguishable from those bearing four doses of either grim or $r p r$. Because expression from cosmid transgenes may be compromised in our transformants, solid conclusions regarding the number of distinct cell death functions uncovered by $\mathrm{H} 99$ cannot be drawn from these results.

In Drosophila and in other species, tight linkage can occur among groups of genes that share closely related functions (for review, see Lawrence 1992; Krumlauf 1994). Typically, the individual members within conserved gene clusters share a common orientation of transcription and a considerable degree of sequence similarity. Therefore, the H99 cell death interval apparently shares some, but not all, of the classic features of a complex: grim, hid, and rpr share commonality of orientation and function, yet outside a very limited stretch these proteins share little or no sequence similarity. Because individual members within a gene cluster are typically thought to have arisen by evolutionary duplication and divergence (for review, see Kenyon 1994) it is possible that organization of the H99 cell death cluster may have evolved by different mechanisms.

\section{Models of apoptosis signaling by grim}

The induction of grim was sufficient to trigger apoptosis in embryos that were homozygous for the H99 deletion. This observation rules out an absolute requirement for either rpr or hid during grim-mediated cell death. Among a number of inducible transgenes tested thus far /Grether et al. 1995|, only rpr and hid also triggered significant apoptosis in the H99 background. Because coexpression of p35 blocks apoptosis triggered by grim, rpr, and hid (Grether et al. 1995; White et al. 1996; W. Nordstrom, P. Chen, H. Steller, and J.M. Abrams, in prep.; this paper), all three might ultimately activate a common pathway involving conserved ICE/CED-3-like proteases that are targets for inactivation by $\mathrm{p} 35$. Moreover, grim induction was able to trigger apoptosis at a time in early development when no such effects were observed with rpr. This 
distinction could reflect differences in cell death signaling that are uncovered during early development. For instance, a negative regulator of $r p r$ that does not block grim might be present at this stage, or alternatively, an effector required for rpr but not for grim might be absent at this stage. These gene products might thus be viewed as parallel switches that can ultimately activate a common circuit of apoptotic downstream effectors. Alternatively, two or more entirely parallel pathways, each of which is blocked separately by p35, could define the effector circuits downstream of these genes. In either case, grim, rpr, and hid might represent alternate switches or nodes that could be activated by similar yet distinct sets of converging apoptotic signals. Preliminary evidence (P. Chen, W. Nordstrom, and J.M. Abrams, unpubl.) to support this notion comes from assays that monitor differential regulation of these gene products in response to stimuli that provoke ectopic cell death.

\section{Materials and methods}

Drosophila stocks

$D f(3 L)$ H99, In $\mid 3 L) h i d^{W R+X 1}$, were described previously (Abbot and Lengyel 1991). Isolation of X14 and X25 was described in Grether (1994) and White et al. (1994) and that of hsrpr46A and hsrpr53 were described in White et al. (1996). GMR-p35 (Hay et al. 1994) was obtained from B. Hay and G. Rubin. The wild-type strain used was Canton $S$, and the parental strain for germ-line transformations was $y w^{67 c 23}$. All genetic symbols are according to Lindsley and Zimm (1992).

\section{Cosmid transformation and phenotypic analysis}

A cosmid from a genomic walk (Grether 1994; White et al. 1994) was determined to span the grim gene. A mixture of $437 \mu \mathrm{g} / \mathrm{ml}$ of cosmid DNA and $100 \mu \mathrm{g} / \mathrm{ml}$ of $\Delta 2-3$ helper plasmid DNA was injected into several thousand yw embryos (Rubin and Spradling 1982). Four independent transformed lines were isolated. Two of these map to the third chromosome (grim-CosB and grim-CosD), one maps to the second (grim-CosA), and one is on the $\mathrm{X}$ Chromosome (grim-CosC). Two of these (lines A and C) were introduced into the $\mathrm{H} 99$ background, and a recombinant of grim-CosD was constructed to obtain w; grim-CosD, $H 99$ ri,p/ $T M 3, S b$ flies. Levels of rescue by grim cosmid, were determined by staining with AO (Abrams et al. 1993) and found to be similar among the three lines, A, C, and D. To construct a line with four grim transgenes in the H99 background, homozygous grim-CosA flies were mated with $w$; CyO/ + ; grim-CosD, H99 $r i, p / T M 3 S b r i, p$ individuals. $C y O, S b$ virgins and male $C y O$; grim-CosD, $H 99, r i, p$ progeny were mated, and in the following generation, individuals of the grim-CosA; grim-CosD, H99, $r i, p / T M 3, S b$ ri,p genotype were selected by eye color and $r i$.

\section{Isolation, characterization, and sequencing of grim cDNA}

A 3-kb HpaI-NotI fragment from the grim cosmid was used to screen an embryonic cDNA library in $\lambda$ gt 10 (Poole et al. 1985). Eight clones with similar sized inserts were isolated from $\sim 500,000$ clones screened. One of these, clone A, was confirmed to map to the $\mathrm{H} 99$ interval by Southern hybridization to both wild-type DNA and DNA isolated from H99 embryos. The insert was subcloned into the EcoRI site of pBluescript SK + and sequenced by dideoxy-DNA sequencing using Sequenase version 2.0 DNA Sequencing Kit (U.S. Biochemical) and ${ }^{35} \mathrm{~S}$ labeled dATP (Amersham).

\section{Southerns and Northern hybridization}

Genomic DNA from adult flies was isolated according to Ashburner (1989). To isolate DNA from homozygous H99 embryos, samples were aged so that all embryos were older than $\sim 18 \mathrm{hr}$ and dechorionated before sorting. At this stage and beyond, mutants can be readily identified by virtue of their head defect and inability to hatch. DNA was isolated from $\sim 300-600$ embryos as in Ashburner (1989) except that the phenol/chloroform extraction was skipped and the DNA was precipitated with 0.5 volume of isopropanol. DNAs from $\sim 100$ sorted H99 embryos per lane were typically used for Southern hybridizations (Sambrook et al. 1989). As expected, probes mapping inside the $\mathrm{H} 99$ interval fail to produce hybridizing signals on H99 DNA, whereas probes outside the interval do. RNA was isolated from 7- to 12 -hr embryos in a procedure similar to Chirgwin et al. (1979) and was processed for Northern hybridizations according to Sambrook et al. (1989).

\section{Histological methods}

AO staining was performed as in Abrams et al. (1993). Embryos were staged according to Campos-Ortega and Hartenstein (1985). TUNEL (Gavrieli et al. 1992) was as described performed performed (White et al. 1994). A grim RNA probe for use in whole-mount in situ hybridizations (Tautz and Pfeifle 1989) was transcribed from the linearized cDNA using the DIG RNA labeling kit (Boehringer Mannheim). Hybridizations were performed on 0- to 16- hr embryos from yw and H99/TM3 stocks. No signal was detected in $\mathrm{H} 99$ homozygotes. In $(3 L)$ hid $^{\mathrm{WR}+\mathrm{X} 1}$ embryos were also examined with the grim probe and identified by their head involution defect (Abbot and Lengyel 1991). To look for possible cross-regulation between grim and rpr, heatshocked HS-grim2.1 (see below) embryos were hybridized with a rpr probe (White et al. 1994), and heated hsrpr46A embryos were hybridized with the grim probe.

Construction of HS-grim transgenic strains and phenotypic analysis

An EcoRI fragment containing grim cDNA was inserted in the sense orientation into the $\mathrm{pCaSpeR} / \mathrm{hsp} 70$ vector /Grether et al. 1995 to generate the HS-grim plasmid. A mixture of $500 \mu \mathrm{g} / \mathrm{ml}$ of HS-grim DNA and $100 \mu \mathrm{g} / \mathrm{ml}$ of $\Delta 2-3$ helper plasmid DNA was injected into yw embryos. Two independent transformants (from a total of seven isolated) were mapped and examined in detail. For heat shock treatment, embryos from homozygous strains were collected at $25^{\circ} \mathrm{C}$, aged at $18^{\circ} \mathrm{C}$, heat-treated in a $39^{\circ} \mathrm{C}$ water bath for $30 \mathrm{~min}$, and allowed to recover at $25^{\circ} \mathrm{C}$ for $1 \mathrm{hr}$. Subsequently, the samples were processed for either AO staining, TUNEL labeling, or in situ hybridization. Embryos from flies of homozygous HS-grim 2.1, HS-grim 3, and HSgrim2.1; $H 99 / T M 3 S b$ were checked for grim-induced cell killing. Embryos from untransformed $y w$ and $H 99 / T M 3 S b$ flies were also subjected to the same heat shock treatment as a control. For comparisons to rpr-induced cell death, homozygous hsrpr46A and hsrpr53A (White et al. 1996) embryos were treated in parallel. To determine lethality, known numbers of 0 - to 8 -hr homozygous embryos were heat-treated and empty egg cases were counted after $24 \mathrm{hr}$ at $25^{\circ} \mathrm{C}$. The results cited are the combined results of two separate trials in which a total of 197 HSgrim embryos and 187 yw embryos were treated in parallel. 
Construction of $p G M R$-grim transgenic strains and phenotypic analysis

An EcoRI fragment containing grim cDNA was cloned into the pGMR vector (Hay et al. 1994) in the sense orientation to generate the pGMR-grim transgene. This plasmid was injected into $y w$ embryos at $500 \mu \mathrm{g} / \mathrm{ml}$, together with the $\Delta 2-3$ transposase helper plasmid at $100 \mu \mathrm{g} / \mathrm{ml}$ to produce transgenic flies as described above. Seven of eight independent lines isolated had rough eyes that were substantially reduced in size, a phenotype consistent with increased cell death in the developing eye. One strain, pGMR-grim1, maps to the second chromosome and shows a representative phenotype that is more severe when homozygous. This strain was mated to pGMR-p35 (Hay et al. 1994 to generate flies homozygous for pGMR-grim1 and pGMR-p35. For scanning electron microscopy, samples were coated with gold-palladium and examined in a JEOL $120-\mathrm{kV}$ electron microscope.

Construction of pMT-grim, pMT-grimORF, cell culture, transfection, and cell death assays

pMT-grim was made by inserting a 1.1-kb EcoRI-Rsal fragment of grim cDNA into EcoRI-BamHI/blunt-digested pRmHa.3 vector (Bunch et al. 1988). The large EcoRI-NcoI fragment of pMT-grim was blunted using Klenow fragment and circularized to generate pMT-grimORF, which includes the hypothetical start codon through 429 bases downstream of the stop codon. Stably transfected cell lines were produced by cotransfection of $2 \mu \mathrm{g}$ of test plasmid with $0.2 \mu \mathrm{g}$ pCohygro /Van der Straten et al. 1989 ) into $1 \times 10^{6}$ Schneider L2 cells (Schneider 1972) cultured in Sf900 II SFM (GIBCO BRL) with $50 \mu \mathrm{g} / \mathrm{ml}$ of gentamycin (Sigma). After transfections with pMT-grim or pMT-grimORF DNA alone, or in combination with a similar amount of pMTp35 plasmid (W. Nordstrom, P. Chen, H. Steller, and J.M. Abrams, in prep.), cells were selected with a supplement of 300 $\mu \mathrm{g} / \mathrm{ml}$ of hygromycin (Sigma). For induction of the metallothionein-responsive promoter, cells were exposed to $700 \mathrm{~mm}$ $\mathrm{CuSO}_{4}$.

For transient transfections, SL2 cells were plated at a density of $1 \times 10^{6}$ cells/well in six-well plates. Transfections were done with CellFECTIN (GIBCO BRL) according to the manufacturer's instruction. Forty-eight hours after transfection, cells from each well were split into two wells, and copper was added to one of the two wells. Two procedures were used to measure apoptosis frequency after gene induction in transiently transfected cells. One measure relies on the appearance of hypodiploid nuclei in flow cytometric assays (Tounekti et al. 1995) of propidium iodide-stained cells. After various treatments, cells were washed off the plates, fixed with $2 \%$ formaldehyde in PBS for 15 min, stained with $50 \mu \mathrm{g} / \mathrm{ml}$ of propidium iodide in the dark at $4^{\circ} \mathrm{C}$, and analyzed within $24 \mathrm{hr}$ on a Becton Dickinson FACScan flow cytometer using LYSIS II software. The alternative method relies on loss of cotransfected reporter gene activity to measure apoptosis (Hsu et al. 1995). An amount of $0.2 \mu \mathrm{g}$ of the reporter plasmid (pActin-LacZ) was cotransfected with $2 \mu \mathrm{g}$ of test plasmids. Forty-eight hours later, samples were induced, and after another $16 \mathrm{hr}, \beta$-gal activity was visualized by fixing cells for 30 min with $2 \%$ formaldehyde and staining with X-gal as described (Hsu et al. 1995).

\section{Acknowledgments}

We thank L. Cherbas for pActin-LacZ plasmid, B. Hay and G. Rubin for pGMR-p35 flies and the pGMR vector, $H$. Kramer for pMT-HA-hook, P. Friesen and L. Miller for p35 DNA, and H. Steller and K. White for the hsrpr strains. We also thank P. Lee, J. Varkey, and K. Plunk for excellent technical assistance. We are grateful to Carol Lewis and Wilshirl Rowan for general help. This work was supported by grants to J.M.A. from the National Institutes of Health (AG12466) and from the Texas Advanced Technology Program (003660061).

The publication costs of this article were defrayed in part by payment of page charges. This article must therefore be hereby marked "advertisement" in accordance with 18 USC section 1734 solely to indicate this fact.

\section{Note added in proof}

The sequence data reported in this paper will appear in GenBank under accession number U61976.

\section{References}

Abbot, M.K. and J.A. Lengyel. 1991. Embryonic head involution and rotation of the male terminalia require the Drosophila locus head involution defective. Genetics 129: 783-789.

Abrams, J.M. 1996. Molecular and genetic control of apoptosis in Drosophila. In Apoptosis in normal development and cancer (ed. M. Slusyer), pp. 171-188, Taylor \& Francis, London, UK.

Abrams, J.M., A. Lux, H. Steller, and M. Krieger. 1992. Macrophages in Drosophila embryos and L2 cells exhibit scavenger receptor-mediated endocytosis. Proc. Natl. Acad. Sci. 89: $10375-10379$.

Abrams, J.M., K. White, L. Fessler, and H. Steller. 1993. Programmed cell death during Drosophila embryogenesis. Development 117: 29-44.

Altschul, S.F., W. Gish, W. Miller, E.W. Myers, and D.J. Lipman. 1990. Basic local alignment search tool. J. Mol. Biol. 215: 403-410.

Ashburner, M. 1989. Drosophila: A laboratory manual. Cold Spring Harbor Laboratory Press, Cold Spring Harbor, NY.

Bump, N.J., M. Hackett, M. Hugunin, S. Seshagiri, K. Brady, P. Chen, C. Ferenz, S. Franklin, T. Ghayur, P. Li, P. Licari, J. Mankovich, L.F. Shi, A.H. Greenberg, L.K. Miller, and W.W. Wong. 1995. Inhibition of ICE family proteases by baculovirus antiapoptotic protein p35. Science 269: 1885-1888.

Bunch, T.A., Y. Grinblat, and L.S. Goldstein. 1988. Characterization and use of the Drosophila metallothionein promoter in cultured Drosophila melanogaster cells. Nucleic Acids Res. 16: 1043-1061.

Campos-Ortega, J.A. and V. Hartenstein. 1985. The embryonic development of Drosophila melanogaster. Springer-Verlag, Berlin, Germany.

Chirgwin, J.M., A.E. Przybyla, R.J. MacDonald, and W.J. Rutter. 1979. Isolation of biologically active ribonucleic acid from sources enriched in ribonuclease. Biochemistry 18: 52945299.

Clem, R. and L.K. Miller. 1994. Control of programmed cell death by the baculovirus genes $p 35$ and iap. Mol. Cell. Biol. 14: 5212-5222.

Clem, R.J., M. Fechheimer, and L.K. Miller. 1991. Prevention of apoptosis by a baculovirus gene during infection of insect cells. Science 254: 1388-1390.

Cleveland, J.L. and J.N. Ihle. 1995. Contenders in FasL/TNF death signaling. Cell 81: 479-482.

Ellis, R.E., J. Yuan, and H.R. Horvitz. 1991. Mechanisms and functions of cell death. Annu. Rev. Cell Biol. 7: 663-698.

Gavrieli, Y., Y. Sherman, and S.A. Ben-Sasson. 1992. Identification of programmed cell death in situ via specific labeling of nuclear DNA fragmentation. J. Cell. Biol. 119: 493-501.

Golstein, P., D. Marguet, and V. Depraetere. 1995a. Fas bridging cell death and cytotoxicity: The reaper connection. Immunol. Rev. 146: 45-56. 
- 1995b. Homology between Reaper and the cell death domains of Fas and TNFRl. Cell 81: 185-186.

Gougen, M. and L. Montagnier. 1993. Apoptosis and AIDS. Science 260: 1269-1270.

Grether, M. 1994. "Molecular genetic analysis of larval visual system development and programmed cell death in Drosophila." Ph.D. thesis, Massachusetts Institute of Technology, Cambridge, MA.

Grether, M., J.M. Abrams, J. Agapite, K. White, and H. Steller. 1995. The head involution defective gene of Drosophila melanogaster and its role in programmed cell death. Genes \& Dev. 9: 1694-1708.

Hay, B., T. Wolff, and G.M. Rubin. 1994. Expression of the baculovirus p35 prevents cell death in Drosophila. Development 120: 2121-2129.

Hsu, H., J. Xiong, and D.V. Goeddel. 1995. The TNF receptor 1 -associated protein TRADD signals cell death and NF-к B activation. Cell 81: 495-504.

Hurle, J.M. 1988. Cell death in developing systems. Methods Achiev. Exp. Pathol. 13: 55-86.

Kenyon, C. 1994. If birds can fly, why can't we? Homeotic genes and evolution. Cell 78: 175-180.

Kerr, J.F.R. and B.V. Harmon. 1991, Definition and incidence of apoptosis: An historical perspective. In Current communications in cell and molecular biology. Apoptosis: The molecular basis of cell death (ed. L.D. Tomei and F.O. Kope), pp. 5-29, Cold Spring Harbor Laboratory Press, Cold Spring Harbor, N.Y.

Kerr, J.F.R., A.H. Wyllie, and A.R. Currie. 1972. Apoptosis: A basic biological phenomenon with wide ranging implications in tissue kinetics. Br. J. Cancer 26: 239-257.

Kovach, M.J., J.O. Carlson, and B.J. Beaty. 1992. A Drosophila metallothionein promoter is inducible in mosquito cells. Insect Mole. Biol. 1: 37-43.

Kramer, H. and M. Phistry. 1996. Mutations in the Drosophila hook gene inhibit endocytosis of the boss transmembrane ligand into multivesicular bodies. $J$. Cell Biol. 133: 1-11.

Krumlauf, R. 1994. Hox genes in vertebrate development. Cell 78: 191-201.

Lawrence, P.A. 1992. The making of a fly: The genetics of animal design. Blackwell Scientific Publications, London, U.K.

Lindsley, D.L. and G.G. Zimm. 1992. The genome of Drosophila melanogaster. Academic Press, San Diego, CA.

Liston, P., N. Roy, K. Tamai, C. Lefebvre, S. Baird, G. Chertonhorvat, R. Farahani, M. Mclean, J.E. Ikeda, A. Mackenzie, and R.G. Korneluk. 1996. Suppression of apoptosis in mammalian cells by naip and a related family of iap genes. Nature 379: 349-353.

Meyaard, L., S.A. Otto, R.R. Jonker, M.J. Mijinster, R.P.M. Keet, and F. Miedema. 1992. Programmed cell death of T cells in HIV-1 infection. Science 257: 217-219.

Miura, M., H. Zhu, R. Rotello, E.A. Hartwig, and J. Yuan. 1993. Induction of apoptosis in fibroblasts by IL-1B-converting enzyme, a mammalian homolog of the $C$. elegans cell death gene ced-3. Cell 75: 653-650.

Oppenheim, R.W. 1991. Cell death during development of the nervous system. Annu. Rev. Neurosci. 14: 453-501.

Poole, S.J., L.M. Kauvar, B. Drees, and T. Kornberg. 1985. The engrailed locus of Drosophila: Structural analysis of an embryonic transcript. Cell 40: 37-43.

Pronk, G.J., K. Ramer, P. Amiri, and L.T. Williams. 1996. Requirement of an ice-like protease for induction of apoptosis and ceramide generation by reaper. Science 271: 808-810.

Rabizadeh, S., D.J. LaCount, P.D. Friesen and D.E. Bredesen. 1993. Expression of the baculovirus p35 gene inhibits mam- malian neural cell death. J. Neurochem. 61: 2318-2321.

Raff, M.C. 1992. Social controls on survival and cell death. $\mathrm{Na}$ ture 356: 397-400.

Rost, B. and C. Sander. 1994. Combining evolutionary information and neural networks to predict protein secondary structure. Proteins 19: $55-72$.

Roy, N., M.S. Mahedevan, M. McLean, G. Shutler, Z. Yaraghi, R. Farahani, S. Baird, A. Besner-Johnson, C. Lefebvre, K. Xiaolin, M. Salih, H. Aubry, K. Tamai, X. Guan, P. Ioannou, T.O. Crawford, P. Jong, L. Surh, J. Ikeda, R.G. Korneluk, and A. Mackenzie. 1995. The gene for neuronal apoptosis inhibitory protein is partially deleted in individuals with spinal muscular atrophy. Cell 80: 167-178.

Rubin, G.M. and A.C. Spradling. 1982. Genetic transformation of Drosophila with transposable element vectors. Science 218: 348-353.

Sambrook, J., E.F. Fritsch, and T. Maniatis. 1989. Molecular Cloning: A laboratory manual. Cold Spring Harbor Laboratory Press, Cold Spring Harbor, NY.

Saunders, J.W. Jr. and J.F. Fallon 1967, Cell death in morphogenesis. In Major problems in developmental biology, led. M. Locke), pp. 289--314. Academic Press, New York, NY.

Schneider, I. 1972. Cell lines derived from the late embryonic stages of Drosophila melanogaster. J. Embryol. Exp. Morphol. 27: 353-356.

Steller, H. 1995. Mechanisms and genes of cellular suicide. Science 267: 1445-1449.

Sugimoto, A., P.D. Friesen, and J.H. Rothman. 1994. Baculovirus p35 prevents developmentally programmed cell death and rescues a ced -9 mutant in the nematode Caenorhabditis elegans. EMBO I. 13: 2023-2028.

Tautz, D. and C. Pfeifle. 1989. A non-radioactive in situ hybridization method for the localization of specific RNAs in Drosophila embryos reveals translational control of the segmentation gene hunchback. Chromosoma 98: 81-85.

Tounekti, O., J. Belehradek, and L.M. Mir. 1995. Relationships between DNA fragmentation, chromatin condensation and changes in flow cytometry profiles detected during apoptosis. Exp. Cell Res. 217: 506-516.

Truman, J. 1984. Cell death in invertebrate nervous systems. Annu. Rev. Neurosci. 7: 171-188.

Van der Straten, A., H. Johansen, M. Rosenberg, and R. Sweet. 1989. Novel hygromycin B selection system for overexpression of a heterologous gene in Drosophila melanogaster cultured cells. Curr. Meth. Mol. Biol. 1: 1-8.

Vito, P., E. Lacana, and L. Dadamio. 1996. Interfering with apoptosis-- $\mathrm{Ca}^{2+}$-binding protein alg-2 and Alzheimers disease gene alg-3. Science 271: 521-525.

White, E. 1996. Life, death, and the pursuit of apoptosis. Genes \& Dev. 10: 1-15.

White, K., M. Grether, J.M. Abrams, L. Young, K. Farrell, and H. Steller. 1994. Genetic control of programmed cell death in Drosophila. Science 264: 677-683.

White, K., E. Tahaoglu, and H. Steller. 1996. Cell killing by the Drosophila gene reaper. Science 271: 805-807.

Williams, G.T. 1991. Programmed cell death: Apoptosis and oncogenesis. Cell 65: 1097-1098.

Wyllie, A.H., I.F.R. Kerr, and A.R. Currie. 1980. Cell death: The significance of apoptosis. Int. Rev. Cytol. 68: 251-306.

Xue, D. and H.R. Horvitz. 1995. Inhibition of the Caenorhabditis elegans cell-death protease CED-3 by a CED-3 cleavage site in baculovirus p35 protein. Nature 377: 248-251.

Zhou, L., H. Hashimi, L.M. Schwartz, and J.R. Nambu. 1995. Programmed cell death in the Drosophila central nervous system midline. Curr. Biol. 5: 784-790. 


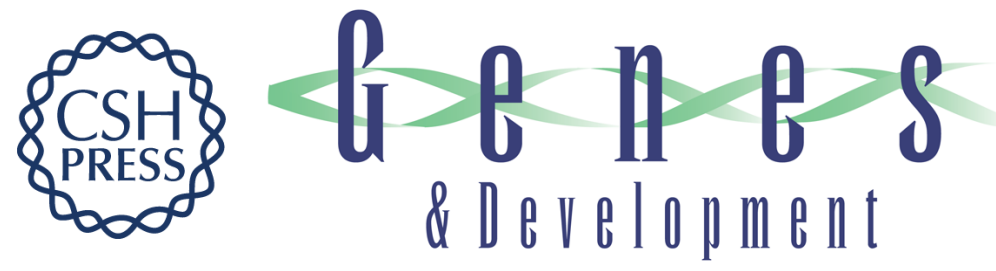

\section{grim, a novel cell death gene in Drosophila.}

P Chen, W Nordstrom, B Gish, et al.

Genes Dev. 1996, 10:

Access the most recent version at doi:10.1101/gad.10.14.1773

References This article cites 50 articles, 18 of which can be accessed free at: http://genesdev.cshlp.org/content/10/14/1773.full.html\#ref-list-1

License

Email Alerting

Receive free email alerts when new articles cite this article - sign up in the box at the top Service right corner of the article or click here.

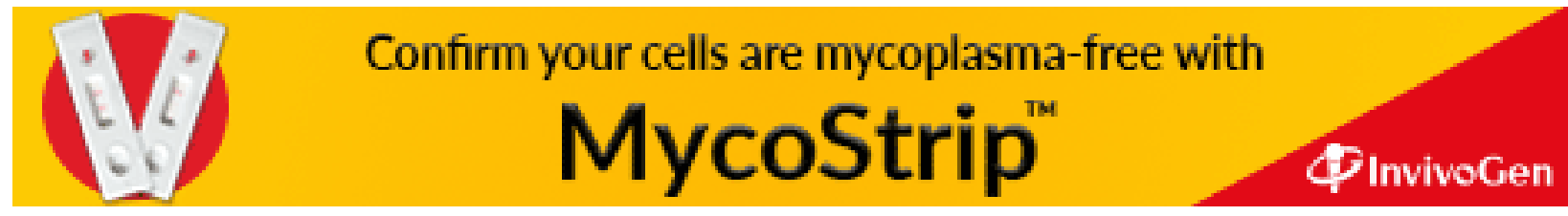

